\title{
DETERMINATION OF THE PLASMA CONCENTRATION OF THE PROTEIN PRODUCT OF THE OB GENE AND LIPID PROFILE IN BOSNIAN TYPE 2 DIABETIC INDIVIDUALS
}

\author{
Šaćira Mandal ${ }^{*}$ \\ University of Sarajevo, Faculty of Pharmacy, Department of Chemistry in Pharmacy, Sarajevo, Bosnia and \\ Herzegovina
}

\begin{abstract}
Leptin is a hormone secreted from adipose tissue (AT) that plays important role in metabolism of carbohydrate, proteins, and lipids. Also, leptin and its receptors are key regulators of body weight and energy metabolism. Previous studies, demonstrated that plasma leptin improved glucose and lipid metabolisms independently of the food intake reduction by decreasing in blood glucose and insulin levels as well as triacylglycerol stores in the body. Objective of this study was to evaluate the relationship between plasma leptin concentration and lipid profile in healthy and diabetic individuals. Twenty-six participants were recruited in the study, 13 newly diagnosed and non-treated Type 2 diabetes (T2D) patients and 13 healthy controls. Metabolic variables including glucose, glycated hemoglobin, lipids: total cholesterol, triacylglycerol, high density lipoprotein, low density lipoprotein and very low-density lipoprotein, and hormone concentrations leptin and insulin were measured. Plasma leptin concentration was an increased significantly $(p<0.001)$ in diabetic patients compared to controls. Values of other biochemical characteristics were significant different between cases and controls $(p<0.001)$. A significant association was demonstrated between leptin with BMI levels in participants $(p<0.05)$ but not between leptin and lipid levels ( $p>0.05)$. Also, strong negative associations were observed between leptin and glucose levels among controls $(p<0.009)$ as well a positive association leptin with HOMA-IS in diabetics $(p<0.05)$. These results suggest that plasma leptin concentrations were affected by the increased levels of glucose, insulin and lipid profile in Bosnian study population. Therefore, leptin can be used as a biomarker of glucose and lipid control in newly diagnosed diabetic patients.
\end{abstract}

Key words: Leptin, lipid profile, Type 2 diabetes

\section{INTRODUCTION}

Obesity represents a risk factor for many diseases such as metabolic syndrome, Type 2 diabetes (T2D), cardiovascular diseases, hypertension and certain neurological disorders $[1,2]$.

Leptin as the product of the obesity (ob) gene is a peptide hormone secreted from adipose tissue (AT) that plays important role in metabolism of carbohydrate, proteins, and lipids [3, 4]. This adipokine has a key function in the regulation of glucose homeostasis as pancreas $\beta$ cells are a major target of leptin actions. In humans, leptin concentrations are correlated with insulin resistance (IR) independently of body weight or adiposity, both in healthy and in diabetes patients $[5,6]$. Also, the concentration of leptin in the body is closely related to fat mass and body mass index (BMI) and often an over-weight person is leptin resistant. This makes that pancreas unable to produce insulin and these persons having higher risk for developing Type 2 diabetes [7-9].

In previously studies, the association of plasma leptin and lipid profile has been contradictory [10-12] Some researchers demonstrated no relation of leptin concentration or its change to the lipids and lipoproteins, while others founded a significant association between leptin with good cholesterol (HDL-C) and as well as triacylglycerol. Also, elevated concentrations of leptin are associated with increased synthesis of cholesterol and its reduced absorption in organism [13].

Objective of this study was to found the relationship between plasma leptin concentration and lipid profile in Bosnian healthy and newly diagnosed Type 2 diabetes.

\section{EXPERIMENTAL}

\subsection{Subjects}

A total of 26 subjects were enrolled in this study: 13 patients with newly-diagnosed and non-treated Type 2 diabetes (T2D) and 13 healthy controls, aged between 35 and 75 years.

The clinically diagnosed T2D participants were as per the American Diabetes Association (ADA) guidelines with a fasting glucose $\geq 7.0 \mathrm{mmol} / \mathrm{L}$ or HbA1c $\geq 6.5 \%$ [14]. The diabetics were newly diagnosed T2D patients and they were not treated with any antidiabetic drugs. Participants with kidney and liver diseases have been excluded from the study. A control group was comprised of 13 healthy, non-obese subjects who had not kidney and liver diseases, and were not taking any medication.

All analyses complied with the principles of the Declaration of Helsinki, and written informed consent was obtained from all the participants. 


\subsection{Anthropometric and biochemical analyses}

Anthropometric measurements, such as height, weight, waist circumference, were taken. Waist circumference was measured halfway between the last rib and the iliac crest with full abdominal relaxation. Height was determined using a measuring tape, and body weight was measured to the nearest $0.1 \mathrm{~kg}$. Body mass index (BMI) calculated by dividing weight $(\mathrm{kg})$ by height squared $\left(\mathrm{m}^{2}\right)$, and individuals with BMI more than $25 \mathrm{~kg} / \mathrm{m}^{2}$ were considered as obese.

Blood samples were collected after overnight fasting in EDTA vacutainers and centrifuged for 10 minutes at 1,000-2,000xg using a refrigerated centrifuge. Plasma samples stored at $-70{ }^{\circ} \mathrm{C}$ until analysis.

Biochemical measurements of glucose, glycated hemoglobin, lipid profile: total cholesterol, triacylglycerol, and high-density lipoprotein) were determined by standard procedures with an autoanalyzer VITROS 350 Chemistry System (OrthoClinical Diagnostic, Rochester, New York, USA). The concentration of low-density lipoprotein cholesterol (LDL-C) was calculated with the Friedewald formula.

Plasma insulin was measured by the immunoenzymometric assay on an AxSYM analyzer (Abbott Laboratories, Abbott Park, IL, USA). Glycohemoglobin (HbA1c) was determined in the whole blood with EDTA by a NGSP-certified affinity separation method, using the NycoCard reader (AxisShield, Oslo, Norway). To assess insulin resistance, the homeostasis model assessment insulin resistance index (HOMA-IR) was calculated according to the formula: fasting insulin $(\mu \mathrm{U} / \mathrm{L}) \times$ fasting glucose $(\mathrm{mmol} / \mathrm{L})$ $/ 22.5$ while HOMA of $\beta$-cell function (HOMA-B) index, evaluates by using the formula: $20 \mathrm{x}$ fasting insulin $(\mu \mathrm{U} / \mathrm{L}) /$ fasting glucose $(\mathrm{mmol} / \mathrm{L})-3.5$ [15]

Leptin was determined by "sandwich" enzyme immunoassay method and using an ELISA kit (Human leptin Immunoassay, Cat. \#EZHL-80SK; EMD Millipore Corporation, Billerica, MA, USA). The principle of the determination of plasma leptin was following for manufacturer assay recommendations.

Data are presented as the medians (interquartile range) because most of the continuous variables were non-parametrically distributed. Differences between groups were analyzed using the Mann-Whitney test. Spearman's correlation analysis was used to explore the correlation between plasma leptin levels and biochemical and clinical characteristics. Statistical analysis was performed with SPSS 17.0 for Windows (SPSS, Chicago, IL, USA). $P$ value below 0.05 was considered as statistically significant.

\section{RESULTS AND DISCUSSION}

The characteristics of T2D patients and control subjects are presented in Table 1 . Values of all the measured traits were significantly different between cases and controls $(\mathrm{p}<0.001)$. The results are consistent to the findings of others in which they were elevated values of glucose, glycated hemoglobin and lipid profile except for HDL whose values were reduced in obese diabetics and non-obese diabetics. Plasma leptin concentrations were increased significantly $(\mathrm{p}<0.001)$ in diabetic patients compared to controls. Also, leptin levels were higher in women than men in diabetes group (data not shown). Possible explanation for this difference is due for different sex hormone status as well as body fat distribution in females and males $[16,17]$.

Table 1. The clinical and biochemical parameters in controls and cases included in the study.

\begin{tabular}{|c|c|c|c|}
\hline Parameters & Controls & Cases & $\boldsymbol{P}^{*}$ \\
\hline Number & 13 & 13 & - \\
\hline Gender (M/F) & $7 / 6$ & $9 / 4$ & - \\
\hline Age (years) & $\begin{array}{c}57 \\
(35-75) \\
\end{array}$ & $\begin{array}{c}64 \\
(35-73) \\
\end{array}$ & 0.001 \\
\hline $\begin{array}{l}\text { Body weight } \\
(\mathrm{kg})\end{array}$ & $\begin{array}{c}79 \\
(74-87) \\
\end{array}$ & $\begin{array}{c}89 \\
(74-129) \\
\end{array}$ & 0.001 \\
\hline $\begin{array}{l}\text { WC } \\
(\mathrm{cm})\end{array}$ & $\begin{array}{c}91 \\
(85-98) \\
\end{array}$ & $\begin{array}{c}107 \\
(90-127) \\
\end{array}$ & 0.002 \\
\hline $\begin{array}{l}\mathrm{BMI} \\
\left(\mathrm{kg} / \mathrm{m}^{2}\right)\end{array}$ & $\begin{array}{c}24 \\
(23-26) \\
\end{array}$ & $\begin{array}{c}31 \\
(26-40) \\
\end{array}$ & 0.001 \\
\hline $\begin{array}{l}\text { Glucose } \\
(\mathrm{mmol} / \mathrm{L})\end{array}$ & $\begin{array}{c}5.50 \\
(5.0-6.0) \\
\end{array}$ & $\begin{array}{c}8.15 \\
(6.5-10.0) \\
\end{array}$ & 0.001 \\
\hline HbA1c (\%) & $\begin{array}{c}5.74 \\
(5.2-6.6) \\
\end{array}$ & $\begin{array}{c}6.99 \\
(6.0-8.2)\end{array}$ & 0.001 \\
\hline $\begin{array}{l}\mathrm{TC} \\
(\mathrm{mmol} / \mathrm{L})\end{array}$ & $\begin{array}{c}5.43 \\
(4.4-6.3) \\
\end{array}$ & $\begin{array}{c}4.56 \\
(3.2-6.3) \\
\end{array}$ & 0.001 \\
\hline $\begin{array}{l}\mathrm{HDL} \\
(\mathrm{mmol} / \mathrm{L})\end{array}$ & $\begin{array}{c}1.23 \\
(0.8-1.7) \\
\end{array}$ & $\begin{array}{c}1.24 \\
(0.6-4.1) \\
\end{array}$ & 0.001 \\
\hline $\mathrm{LDL}(\mathrm{mmol} / \mathrm{L})$ & $\begin{array}{c}3 \cdot 38 \\
(1.2-5 \cdot 5) \\
\end{array}$ & $\begin{array}{c}2.67 \\
(1.3-4.8) \\
\end{array}$ & 0.001 \\
\hline VLDLC (mmol/L) & $\begin{array}{c}0.66 \\
(0.5-1.0) \\
\end{array}$ & $\begin{array}{c}0.96 \\
(0.5-1.8) \\
\end{array}$ & 0.001 \\
\hline TAG (mmol/L) & $\begin{array}{c}1.78 \\
(0.6-4.4) \\
\end{array}$ & $\begin{array}{c}2.05 \\
(1.1-3.9) \\
\end{array}$ & 0.001 \\
\hline Insulin $(\mu \mathrm{U} / \mathrm{L})$ & $\begin{array}{c}7.39 \\
(3.7-10.3) \\
\end{array}$ & $\begin{array}{c}9.97 \\
(3.4-18.6) \\
\end{array}$ & 0.01 \\
\hline Leptin (ng/L) & $\begin{array}{c}10.96 \\
(4.4-26.4) \\
\end{array}$ & $\begin{array}{c}15.94 \\
(5.3-29.0) \\
\end{array}$ & 0.001 \\
\hline HOMA-IR & $\begin{array}{c}1.77 \\
(0.8-2.7) \\
\end{array}$ & $\begin{array}{c}3 \cdot 75 \\
(1.2-7.4) \\
\end{array}$ & 0.01 \\
\hline HOMA-B & $\begin{array}{c}23.98 \\
(10.5-35.7) \\
\end{array}$ & $\begin{array}{c}20.73 \\
(6.9-46.1)\end{array}$ & 0.02 \\
\hline
\end{tabular}

Values represent medians (lower-upper quartile). WC-wais circumvent; BMI-body mass index; HbA1c-glycated hemoglobin; TC-total cholesterol; HDL-high density lipoprotein cholesterol; LDL-low density lipoprotein cholesterol; VLDLC- very low-density lipoprotein cholesterol; HOMA-IR-homeostasis model assessment insulin resistance index; HOMA-B- homeostasis model assessment of $\beta$-cell function index. *Significance of difference in Mann-Whitney test for data following non-normal distributed and t-test for norma distributed data.

Previous reported data suggest that leptin levels unchanged, reduced and increased in Type 2 diabetes $[2-4,9,11]$. The conflicting results of the studies not surprising given that population differed to obesity, age, gender, and ethnic or races. Higher leptin concentrations lead to leptin resistance which plays as major role in the development insulin resistance in obese T2 diabetics. It is also showed that leptin mediate both insulin secretion and sensitivity in peripheral tissues including pancreas, liver, and skeletal muscles by increased expression of its receptors [16].

The relationship between leptin levels and anthropometric, clinical and biochemical features was 
also explored. Negatively significant association was found between leptin and glucose levels in control subjects $(\mathrm{p}<0.01)$, and positive association of leptin with HOMA-IR among diabetic patients (Figures 1 and 2). In line the results of others, it was demonstrated a positive association between leptin levels with BMI in participants (Figure 3) but not between leptin and lipid concentrations $(\mathrm{p}>0.05)$.

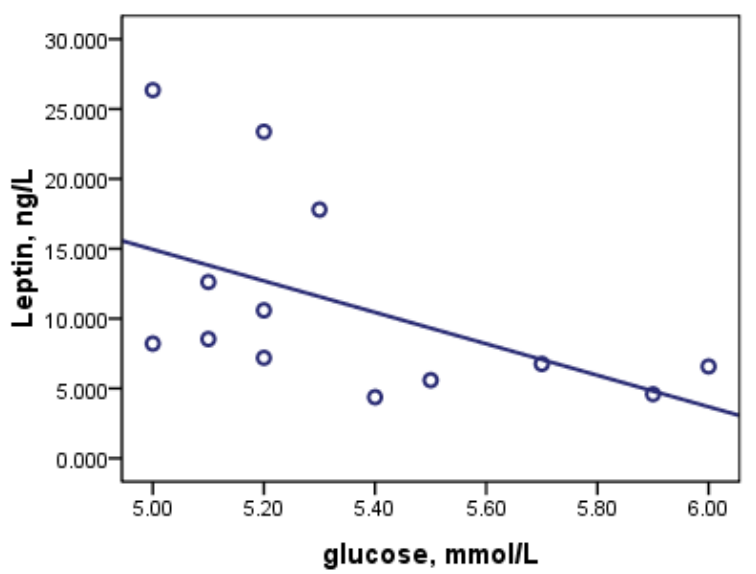

Figure 1. The Spearman's correlation between leptin and glucose levels in controls $(\mathrm{r}=-0.687, \mathrm{p}=0.009)$.

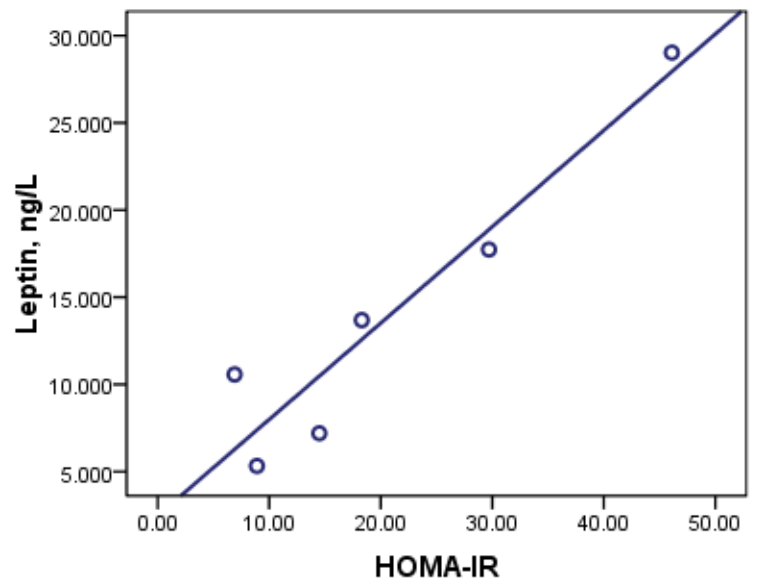

Figure 2. The Spearman's correlation between leptin levels and HOMA-IR in cases $(\mathrm{r}=0.829, p=0.042)$.

The exact role of leptin in impaired glucose homeostasis and altering insulin sensitivity in T2D are not fully elucidated since IR is the major risk factor for the development of $\mathrm{T}_{2}$ diabetes. In the diabetic patients, strongly association leptin with HOMA-IS level was demonstrated ( $p=0.042)$ (Fig.2). Previous findings showed that in obese T2D patients leptin was ineffective in improving insulin sensitivity due to lower improvements of glycated hemoglobin concentrations and poor glycemic control, and the fact that obese individuals have increase plasma leptin levels which indicate a leptin resistance. Also, there are evidence that the protein product of the $o b$ gene signals directly on $\beta$-cells might suppress insulin synthesis and release [19]. In addition, a relative insulin deficiency in Type 2 diabetic subjects cause disturbances in leptin levels since the insulin is an important stimulator of leptin production [20].

The strong association between BMI and plasma leptin concentrations was reported a number studies in insulin resistant and obese T2 diabetics.

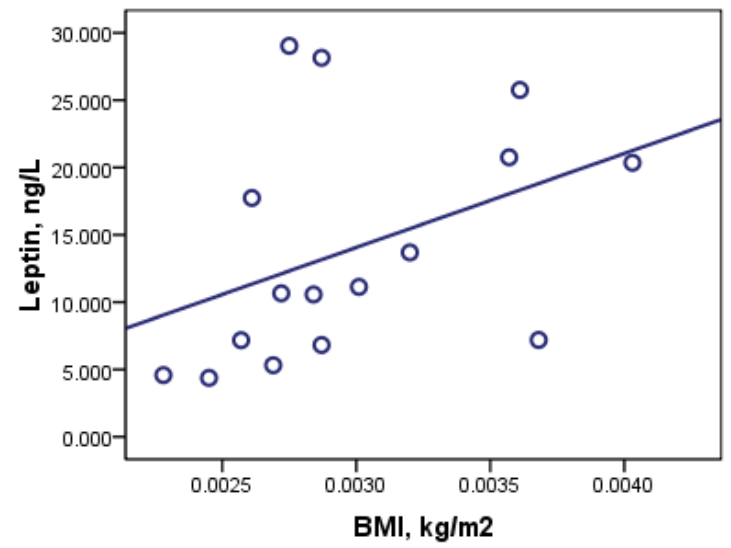

Figure 3. The Spearman's correlation between leptin levels and BMI in all participants $(\mathrm{r}=0.543, p=0.030)$.

In this work, a similar strong correlation was observed between plasma leptin with BMI levels ( $\mathrm{p}=0.009$ ) (Fig.3). Previous studies have been shown that leptin plasma concentrations are dependent of adiposity, fat distribution and fat cell size in T2D patients [11, 17-19]. The obesity and impaired glucose tolerance might cause in early increase in leptin biosynthesis and release from adipocytes. However, there is still controversy concerning circulating leptin concentrations in Type 2 diabetes [20-22].

Considering these and results of the others, elevated plasma leptin concentrations together with impaired lipids metabolism in obese uncontrolled T2D patients could be a potential target for further treatment [20, 23-25].

\section{CONCLUSION}

The results of this preliminary study suggest that plasma leptin concentrations were assumed by the increased levels of glucose, insulin and lipid profile in Bosnian study population. Therefore, leptin can be used as a biomarker of glucose and lipid control in newly diagnosed diabetic patients. Future, larger population-based studies are needed to clarify the role of the protein product of the $o b$ gene on glucose and lipids levels in T2D risk.

\section{REFERENCES}

1. American Diabetes Association, "Obesity Management for the Treatment of Type 2 Diabetes", Diabetes Care, vol. 39, suppl. 1, pp. S47-S51, Jan. 2016. https://doi.org/10.2337/dc16-Soog

2. N. Katsiki, D.P. Mikhailidis, M. Banach, "Leptin, cardiovascular diseases and type 2 diabetes mellitus," 
Acta Pharmacol. Sin., vol. 39, pp. 1176-1188, Jun. 2018.

https://doi.org/10.1038/aps.2018.40

3. A. Sarı, M.B. Sadeq, "The relationship the leptin hormone, obesity and diabetes," Physical Sciences, vol. 15, no. 2, pp. 40-48, Apr. 2020.

Retrieved from:

https://dergipark.org.tr/en/pub/nwsaphysic/issue/538 $\underline{88 / 701533}$

Retrieved on: Sep. 15, 2021

4. T.H. Meek, G.J. Morton, "The role of leptin in diabetes: metabolic effects," Diabetologia, vol. 59, no. 5, pp. 928-932, May. 2016. https://doi.org/10.1007/s00125-016-3898-3

5. J. Seufert, "Leptin effects on pancreatic beta-cell gene expression and function," Diabetes, vol. 53, suppl. 1, pp. S152-S158, Feb. 2004 https://doi.org/10.2337/diabetes.53.2007.S152

6. T. Shiuchi et al., "Induction of glucose uptake in skeletal muscle by central leptin is mediated by muscle $\beta_{2}$-adrenergic receptor but not by AMPK," Sci. Rep., vol. 7, no. 1, article no. 15141, Nov. 2017. https://doi.org/10.1038/s41598-017-15.548-6

7. A.M. D'souza, U.H. Neuman, M.M. Glavas, T.J. Kieffer, "The glucoregulatory actions of leptin," Molecular Metabolism, vol. 6, no. 9, pp. 1052-1065, Sep. 2017. https://doi.org/10.1016/j.molmet.2017.04.011

8. T.M. Moonishaa et al., "Evaluation of leptin as a marker of insulin resistance in type 2 diabetes mellitus," Int. $J$ Appl. Basic Med. Res., vol. 7, no. 3, pp. 176-180, 2017. https://doi.org/10.4103\%2Fijabmr.IJABMR $278 \quad 16$

9. L. Marroquí et al., "Role of leptin in the pancreatic $\beta$-cell: effects and signaling pathways," J. Mol. Endocrinol., vol. 49, no. 1, pp. R9-R17, 2012. https://doi.org/10.1530/jme-12-0025

10. M.A. Buyukbese et al., "Leptin levels in obese women with and without type 2 diabetes mellitus," Mediators of Inflammation, vol. 13, no. 5/6, pp. 321-325, Oct./Nov. 2004. https://doi.org/10.1080/09629350400008828

11. W.I. Sivitz et al., "Leptin and body fat in type 2 diabetes and monodrug therapy," The Journal of Clinical Endocrinology \& Metabolism, vol. 88, no. 4, pp. 1543-1553, Apr. 2003. https://doi.org/10.1210/jc.2002-021193

12. Y. Minokoshi, C. Toda, S. Okamoto, "Regulatory role of leptin in glucose and lipid metabolism in skeletal muscle," Indian J. Endocrinol. Metab., vol. 16, suppl. 3, pp. S562-S568, Dec. 2012.

Retrieved from:

https://pubmed.ncbi.nlm.nih.gov/23565491/ Retrieved on: Sep. 15, 2021

13. L. O'Rourke, S.J. Yeaman, P.R. Shepherd, "Insulin and leptin acutely regulate cholesterol ester metabolism in macrophages by novel signaling pathways," Diabetes, vol. 50, no. 5, pp. 955-961, May 2001. https://doi.org/10.2337/diabetes.50.5.955

14. American Diabetes Association, "Classification and Diagnosis of Diabetes: Standards of Medical Care in
Diabetes-2021," Diabetes Care 2021, vol. 44, suppl. 1 pp. S15-S33, 2021.

https://doi.org/10.2337/dc21-Soo2

15. D.R. Matthews et al., "Homeostasis model assessment: insulin resistance and beta-cell function from fasting plasma glucose and insulin concentrations in man," Diabetologia, vol. 28, no. 7, pp. 412-419, Jul. 1985 https://doi.org/10.1007/bfo0280883

16. S. Zhao, C.M. Kusminski, J.K. Elmquist, P.E. Scherer "Leptin: less is more," Diabetes, vol. 69, no. 5, pp. 823-829, May 2020 https://doi.org/10.2337/dbi19-0018

17. W. Liu et al., "Serum leptin, resistin, and adiponectin levels in obese and non-obese patients with newly diagnosed type 2 diabetes mellitus: A population-based study," Medicine, vol. 99, no. 6, article no. e19052, Feb. 2020. https://doi.org/10.1097/MD.0000000000019052

18. R. Farooq et al., "Type 2 diabetes and metabolic syndrome - adipokine levels and effect of drugs," Gynecol. Endocrinol., vol. 33, no. 1, pp. 75-78, 2017. https://doi.org/10.1080/09513590.2016.1207165

19. O. Gruzdeva, D. Borodkina, E. Uchasova, Y. Dyleva, O. Barbarash, "Leptin resistance: underlying mechanisms and diagnosis," Diabetes Metab. Syndr. Obes., vol. 12, pp. 191-198, Jan. 2019. https://doi.org/10.2147/DMSO.S182406

20. M. Obradovic et al., "Leptin and Obesity: Role and Clinical Implication," Front. Endocrinol., vol. 12, article no. 585887, May 2021. https://doi.org/10.3389/fendo.2021.585887

21. H. Zuo et al., "Association between serum leptin concentrations and insulin resistance: a populationbased study from China," PLOS ONE, vol. 8, no. 1, article no. e54615, Jan. 2013. https://doi.org/10.1371/journal.pone.0054615

22. J. Huang, X. Peng, K. Dong, J. Tao, Y. Yang, "The association between insulin resistance, leptin, and resistin and diabetic nephropathy in type 2 diabetes mellitus patients with different body mass indexes," Diabetes Metab. Syndr. Obes. Targ. Ther., vol. 14, pp. 2357-2365, May 2021. https://doi.org/10.2147/DMSO.S305054

23. M. Mehrdad et al., "Association of FTO rs9939609 polymorphism with serum leptin, insulin, adiponectin, and lipid profile in overweight adults," Adipocyte, vol. 9 , no. 1 , pp. 51-56, Dec. 2020. https://doi.org/10.1080/21623945.2020.1722550

24. S. Mandal, "New molecular biomarkers in precise diagnosis and therapy of type 2 diabetes," Health Technol., vol. 10, pp. 601-6o8, May 2020. https://doi.org/10.1007/s12553-019-00385-6

25. C. Vavruch et al., "Using proximity extension proteomics assay to discover novel biomarkers associated with circulating leptin levels in patients with type 2 diabetes," Sci. Rep., vol. 10, no. 1, article no. 13097, Aug. 2020. https://doi.org/10.1038/s41598-020-69473-2 